ORIGINAL ARTICLE

\title{
The effect of functional and supportive classic strength trainings in basketball players on aerobic strength, dynamic balance and body composition
}

\author{
Ali Türker ${ }^{1 \mathrm{ACDE}}$, Oğuzhan Yüksel ${ }^{2 \mathrm{ABD}}$ \\ ${ }^{1}$ School of Physical Education and Sports, Muş, Turkey \\ ${ }^{2}$ School of Physical Education and Sports, Kütahya, Turkey
}

Authors' Contribution: A - Study design; B - Data collection; C - Statistical analysis; D - Manuscript Preparation; E - Funds Collection.

\begin{abstract}
Purpose:

It has been aimed to investigate the effects of functional and supportive classic strength trainings in basketball players on aerobic strength, dynamic balance and body composition.

Material: $\quad$ In the study, the test group has performed functional + supportive classic strength training $(n=15 ; 20$, $8 \pm 1,7$ year) three days in a week for eight weeks. Within the process, test and control groups have also continued basketball technical tactics trainings two days in a week. The control group ( $n=15 ; 21,06 \pm 1,9$ year) has not performed any strength training. The participants have been tested in terms of height, body weight, skinfold calipers, watt bike pro ramp aerobic capacity test and libra see saw balancing board test. When identifying the percentage of body fat, lunge formula has been used. The data has been evaluated with Repetitive Measurements Anova Test.

Results: In comparing the group $\mathrm{x}$ time interaction, while the developmental difference in the values of $\mathrm{VO}_{2 \mathrm{~m}}$ Estimate ( $\mathrm{mg} / \mathrm{kg} / \mathrm{min})$, MET, the percentage of body fat and Left foot lateral balance test has been found out statistically substantial in test and control groups, no significant difference in lateral balance on both feet, right foot lateral balance the measurements and transfer balance measurements on both feet has been found out.

Conclusions: $\quad$ As a consequence, it has been seen that functional and supportive strength trainings have contributed to the percentage of body fat, aerobic capacity and dynamic balance. In the planning of yearly training it has been seen that functional strength trainings in preparation phase will contribute to the development levels of basketball players.

Keywords: $\quad$ functional strength trainings, dynamic balance, body composition, aerobic capacity.
\end{abstract}

\section{Introduction}

The functional training has been attracting the attention as an approach which has enriched its popularity day by day throughout world and placed in training modalities by several teams and sportsmen. When examining the content of functional training generally, it has been seen that it includes close movements to the movements of specific sports branch performed by sportsmen [1]. ACSM (American College of Sports Medicine) Functional Training; just as neuromotor trainings; has been described as a training method including balance, coordination, mobility, agility and proprioceptive skills [2]. The thing that mainly operationalizes functional training is to provide the transfer of existing performance parameters to sportive performance in a successive way [3]. Therefore, it aims to train sportsmen with the help of the patterns based on the movements in real life (e. g. flexibility, mobility, throwing, bending and spinning etc. ) $[4,5]$ It has been seen that functional training is more effective than classic resistance and strength trainings and that is because it has been performed in multi junction and different platforms [6]. It is important to create kinetic chains well in transferring existing motor skills. Particularly traditional resistance trainings,

(c) Ali Türker, Oğuzhan Yüksel, 2021

doi:10.15561/26649837.2021.0107 these approaches are less stabile compared to functional trainings, provide muscle motor control and this situation makes functional training important in transferring of performance to the competition [7].

Functional training has been generally confused with classic resistance and strength trainings. In limited studies that have been made before, it has been identified that in the sportsmen who are performing especially high intensity functional training both they have achieved approximate values to strength sportsmen and resistance sportsmen are able to generate power against tiredness [8]. Gencer et al have stated that there is no effect of core training model in age group between 9 and 12 on free style swimming performance [9]. It has been known that it also provides increase in efficiency in exercises with combined and multi junction [10]. In the exercises performed in conditions that are not stabile instead of isolated exercises, it has been seen that there are more achievements in the movements which are taken off, balancing and multijunction movements [11]. None the less, the efficiency of classic exercises should be considered in the parameters of peak strength and time on the ground and dominant strength $[12,13]$.

As well as the balance complex is a motor skill, it is also a determinant criterion in athletic performance and where auditory, sensory and depth perceptions need 
to work coordinatively [14]. It has been known that functional training is able to improve directly static and dynamic balance regardless of a certain age range [15]. It is known that functional training as dynamic movement chain is increasing the quality of individual's movement because it empowers rebalancing, junctions and tendons and it also develops proprioceptive system [11, 14]. It has been observed that because functional exercises and warm-ups are far from isolation and in an active-dynamic state, they have developed neuromuscular postural control and postural activation protecting sportsmen from injuries $[16,17,18]$. To train sportsmen by using functional movements increases the junction mobility and this provides sportsmen to create more qualified movement chains and decrease injury risks. The balance and stability disorders occurred especially in developmental periods of young sportsmen can be reduced with functional movement exercises [19]. Again, it is known that functional exercises can prevent injuries and gain favor against posture disorders in sportsmen [20].

Specifically balance motor skill takes an important place in basketball branch. It has shown that the basketball players who have active balance and balancing skills are able to have the percentage of shots with average relation [21]. It has been stated that dynamic balance is a non-neglectable concept for trainers, sportsmen and researchers interested in basketball [22]. Both dynamic and static balance skills have been used for basketball branch [23]. Dynamic balance can be described as the balancing skill of sportsmen' center of gravity against a surface or stimulus. It has been seen that articulations and tendons have great role in this balancing [24]. The importance of sub extremity anatomy cannot be debuted in terms of sportsmen's dominating each other [25]. It has been seen that most of the low extremity injuries are caused by lack of dynamic balance skill [26]. It has been stated in balance exercises implemented on basketball players that dynamic balancing is important, and they develop different balancing strategies in every competitor level [27]. It has been seen in functional exercises and functional balancing and stability exercises that sportsmen can improve low kinematics and they are able to decrease injury risks $[28,29,30]$. It has been identified that the basketball players whose static balance values are high have contributed to game scales in a positive way [31]. By suggesting that balance and flexibility should be integrated into training programs because there are sudden changes of direction in basketball, it has been thought that it will affect success of sportsmen and their teams in a positive way $[31,32,33]$.

Aerobic strength that has been defined as oxygen amount used in unit of time has drawn attention as an important factor for sportive performance [34]. Anaerobic and aerobic power have an important place in basketball branch [35]. Besides improving $\mathrm{VO}_{2 \max }$ and lactate levels, it is necessary to develop aerobic performance for running economy as well [36]. Basketball branch has highly intensive episodic game structure in literature [37]. Even though using explosive qualifications dominantly ensures more anaerobic qualifications, basketball is defined as an aerobic based game in which anaerobic qualifications are dominant [38]. In that, sportsmen need to pull together in short resting time. In aerobic metabolism, basketball has a vital role in producing energy and providing durableness. While 60 percentage of the durations when the ball is played actively in basketball competition is consumed for low intensity activity is consumed, it has been stated that 15 percentage of it is consumed for high intensity activities [39].

When examining anthropometric values of sportsmen, we see that basketball players are generally tall and weighty. However, it has been seen that the fat centages of this mass are between 6 and 15 in elite sportsmen [40, 41]. It has been observed that sub extremity fat rates are lower in sportsmen whose aerobic qualifications are dominant. It can be thought that sub extremity fat rates of basketball players are higher [42]. Serin and Ziyagil (2020) in their study have stated that there is a decrease in fat percentage of sportsmen at the end of 8 weeks traditional squat eccentric strength training [43].

The study has been designated with the aim of investigating the effects of functional training approach on aerobic power, dynamic balance and body composition as an identified periodizing result.

\section{Material and Methods}

\section{Participants}

In the research, while test group has implemented basketball + functional + supportive classic strength training $(\mathrm{n}=15 ; 20,8 \pm 1,7$ year, 196, $4 \pm 8,6 \mathrm{~cm}, 99,08 \pm$ $13,3 \mathrm{~kg}$ ), on the other hand control group has implemented only basketball training $(\mathrm{n}=15 ; 21,06 \pm 1,9$ year, 190,27 \pm $5,9 \mathrm{~cm}, 96,3 \pm 11,2 \mathrm{~kg}$ ). Healthy and volunteer participants who have taken place actively in basketball branch for five years and struggled in intercollegiate leagues have participated in our study.

\section{Research Design}

Initially verbal and oral explanations about the research to be implemented and the measurements to be sized have been made to the individuals participated in the study. The individuals who have accepted to participate in the study have been provided to fill "Volunteer Consent Form". Before the test, a standard gradual warm-up for fifteen minutes has been implemented for each. All tests have been made on the same day and checked by the same researchers and recorded. Training protocol suitable for the defined characteristics of the groups has been implemented.

\section{Data Collection Process}

Watt bike Pro Ramp Test Protocol:

Aerobic capacity of the participants can be identified in Watt bike ramp test. Initial watt value according to the active level of the participants in their sports life and their body weight has been specified in ramp test (Table 1). 20 watts increase in each 1 minute has been seen during the implementation of the test. According to Table 1 , the participants who have 160 watt and over value in test protocol have been subjected to test 12 fractionally. 
Air resistance settings have been implemented in a suitable way to Table 2 for the participants during the test. According to cadence value in each fraction, the participant has been provided to pedal. It has been stated that the participants can optionally terminate the test when needed. At the end of the test, $\mathrm{VO}_{2 \max }$ estimate and MET values have been recorded on watt bike pro digital screen (Figure 1).

When comparing direct measurements, estimated VO2 values used in watt bike pro can give a good guess $[ \pm 6 \%]$. Estimated $\mathrm{VO}_{2 \max }$ formula value in the study conducted by Störer et al. has been used by watt bike pro [44, 45].

Body Composition (Fat Measurement);
In our research body fat percentage has been identified by using skinfold calipers (Holtain, UK). Skinfold calipers values have been recorded by measuring the right side of the participants' body twice from seven standard areas (Biceps, Triceps, Pectoralis, Sub-scapula, Abdominus, Supra-iliac and Quadriceps). Body fat percentage (\%) has been calculated by using skinfold calipers values taken from seven areas of the body (Lange formula; [(Biceps + Triceps + Pectoralis + Sub scapula + Suprailic + Quadriceps) x (0.097) + 3.64] [46].

Dynamic Balance Test Protocol:

Libra see saw balancing board test stand produced by Easy Tech (balancing board; computer set placed on
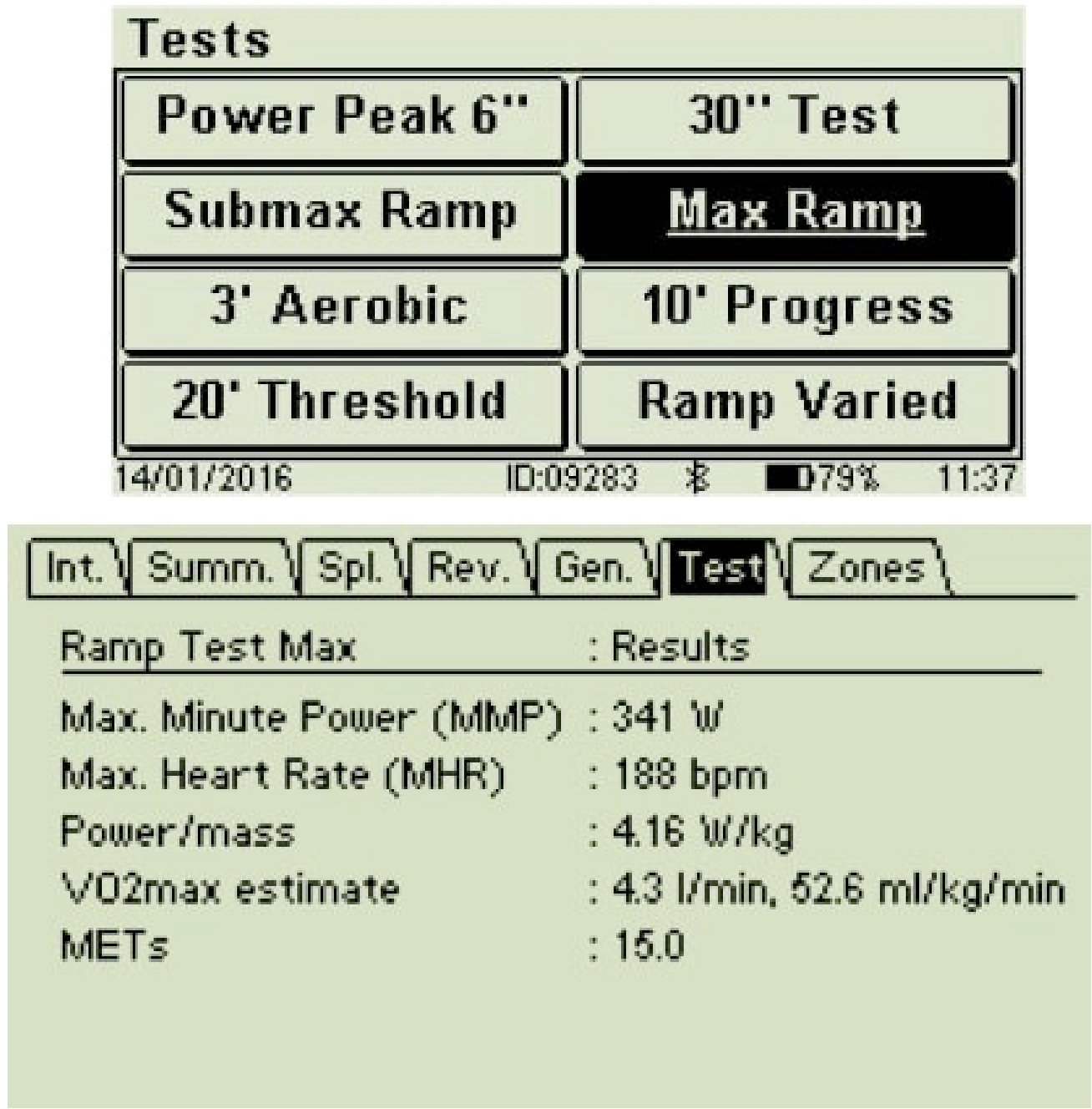

Figure. 1. Screenshots of watt bike pro Test Program

Table 1. Initial Watt Value

\begin{tabular}{llll}
\hline $\begin{array}{l}\text { Initial Watt Value } \\
\text { Weight }(\mathbf{k g})\end{array}$ & Club Level & National Level & World Class Level \\
\hline$<50$ & 120 & 140 & 160 \\
$50-59$ & 140 & 160 & 180 \\
$60-69$ & 160 & 180 & 200 \\
$70-79$ & 180 & 200 & 220 \\
$80+$ & 200 & 220 & 240 \\
\hline
\end{tabular}


Table 2. Watt bike 12 graded ramp test (Aerobic capacity)

\begin{tabular}{lllllllllllll}
\hline \multicolumn{1}{l}{ Watt bike 12 graded ramp test (Aerobic capacity) } \\
Watts & $\mathbf{1 6 0}$ & $\mathbf{1 8 0}$ & $\mathbf{2 0 0}$ & $\mathbf{2 2 0}$ & $\mathbf{2 4 0}$ & $\mathbf{2 6 0}$ & $\mathbf{2 8 0}$ & $\mathbf{3 0 0}$ & $\mathbf{3 2 0}$ & $\mathbf{3 4 0}$ & $\mathbf{3 6 0}$ & $\mathbf{3 8 0}$ \\
\hline Air Resistance & 1 & 2 & 3 & 4 & 4 & 5 & 5 & 6 & 6 & 7 & 8 & 9 \\
Cadence & 92 & 89 & 91 & 89 & 92 & 89 & 92 & 90 & 92 & 91 & 91 & 91 \\
Watts & 180 & 200 & 220 & 240 & 260 & 280 & 300 & 320 & 340 & 360 & 380 & 400 \\
Air Resistance & 1 & 2 & 3 & 4 & 4 & 5 & 5 & 6 & 6 & 7 & 8 & 9 \\
Cadence & 96 & 93 & 95 & 93 & 96 & 93 & 96 & 94 & 96 & 95 & 95 & 95 \\
Watts & 200 & 220 & 240 & 260 & 280 & 300 & 320 & 340 & 360 & 380 & 400 & 420 \\
Air Resistance & 1 & 2 & 3 & 4 & 4 & 5 & 5 & 6 & 6 & 7 & 8 & 9 \\
Cadence & 103 & 98 & 100 & 98 & 101 & 98 & 101 & 99 & 101 & 100 & 100 & 100 \\
\hline
\end{tabular}

the platform with $43 \mathrm{~cm}$ length, $42 \mathrm{~cm}$ width and $65 \mathrm{~cm}$ height) to identify dynamic balance stability has included two parts. Balancing board is activated in an integrated way to the system by connecting to EasyTech2.2001-2.0 computer software via USB interface. It has been transferred to analogue-digital convertor card with potentiometer via electric signals with $0,1^{0}$ maximum measuring error and in \pm 15 slant range in stabilimeter sagittal plan. In interface of EasyTech2.2001-2.0 software, balancing score has been measured based on swinging in balance position (Figure. 2) [47]. Plastic apparat which can be adjustable as $10 \mathrm{~cm}, 25 \mathrm{~cm}$ and $40 \mathrm{~cm}$ with difficulty levels and modified in sub surface of Libra balancing board is available. $40 \mathrm{~cm}$ apparat has been preferred as difficulty level for the participants. Each participant has started Libra see saw balancing board with single foot by placing on balancing board especially right foot on the center at the beginning of the test. It has been provided to implement three more tries with other foot by resting for five minutes after three tries. The same protocol has been performed as both feet lateral and both feet transfer. Trying scores have been recorded [48].

\section{Training Protocol}

Test group has implemented functional training three days in a week (Monday, Wednesday, Friday) for eight weeks. In addition to functional training program, supportive classic strength training has been included twice a week (Tuesday-Thursday) between third and eighth week. Test and control groups have also participated in basketball combined technic, tactics and shot trainings twice a week within 8 weeks in the condition of its extent parallel to its intension.

A-Functional Training (1st and 2nd Week): The training program including 10 stations created by the participants has been performed circularly. After the defined station has been implemented for 30 seconds, they have switched to the other station. The participants have made the performance in all stations. Three sets have been implemented in total. 1- or 2-minutes rest between the sets and 30 seconds rest between the stations have been given. Air squat, push up, lunge, rope swinging (12 kg), skipping rope, Tire\& sledgehammer $(10 \mathrm{~kg})$, crunch, tire flips, hyper extension, box jumps $(40 \mathrm{~cm})$ performances have been implemented with station method. In circular training modelling the station approach by Sperlich et al. and resting protocol have been preferred [49].

B-Functional Training (3rd and 4rd Week): The training program including 10 stations created by the participants has been performed circularly. After the defined station has been implemented for 30 seconds, they have switched to the other station. The participants have made the performance in all stations. Four sets have been implemented in total. 1- or 2-minutes rest between the sets and 30 seconds rest between the stations have been given. Burpees, Plank, box jumps $(40 \mathrm{~cm})$, Dumbbell Push-Up into a Row, throwing a medicine ball on the ground $(5 \mathrm{~kg})$, rope swinging $(12 \mathrm{~kg})$, crunch, superman exercise, skipping rope, TRX- rowing performances have been implemented with station method. In circular training modelling the station approach by Sperlich et al. and resting protocol have been preferred [49].

C-Functional Training (5th and 8th Week): The training program including 10 stations created by the participants has been performed circularly. After the defined station has been implemented for 30 seconds, they have switched to the other station. The participants have made the performance in all stations. Four sets have been implemented in total. 1- or 2-minutes rest between the sets and 30 seconds rest between the stations have been given. Tire \& sledge hammer (10 kg), Ab Roller crunch, TRXpush up, hyper extension, throwing a medici ne ball on the ground (5 kg), skipping rope, dynamic plank, pull up, Bulgarian split squat, rope swinging $(12 \mathrm{~kg})$ performances have been implemented with station method. The station approach by Sperlich et al. and resting protocol have been preferred (Table 3) [49].

A-Strength Training (3th and 4th Week): The participants have implemented Back squat and dead lift movements. Suitably to traditional strength training, 3 sets with 60 percentage of 1 max turn; 10 turns have been implemented. 30-45 seconds rest between sets and 1-2 minutes rest between stations have been given (Table 3 ) [50].

B-Strength Training (5th and 6th Week): The participants have implemented Back squat and dead lift movements. Suitably to traditional strength training, 4 sets with 70 percentage of 1 max turn; 10-12 turns have been implemented. 60 seconds rest between sets and 1-2 

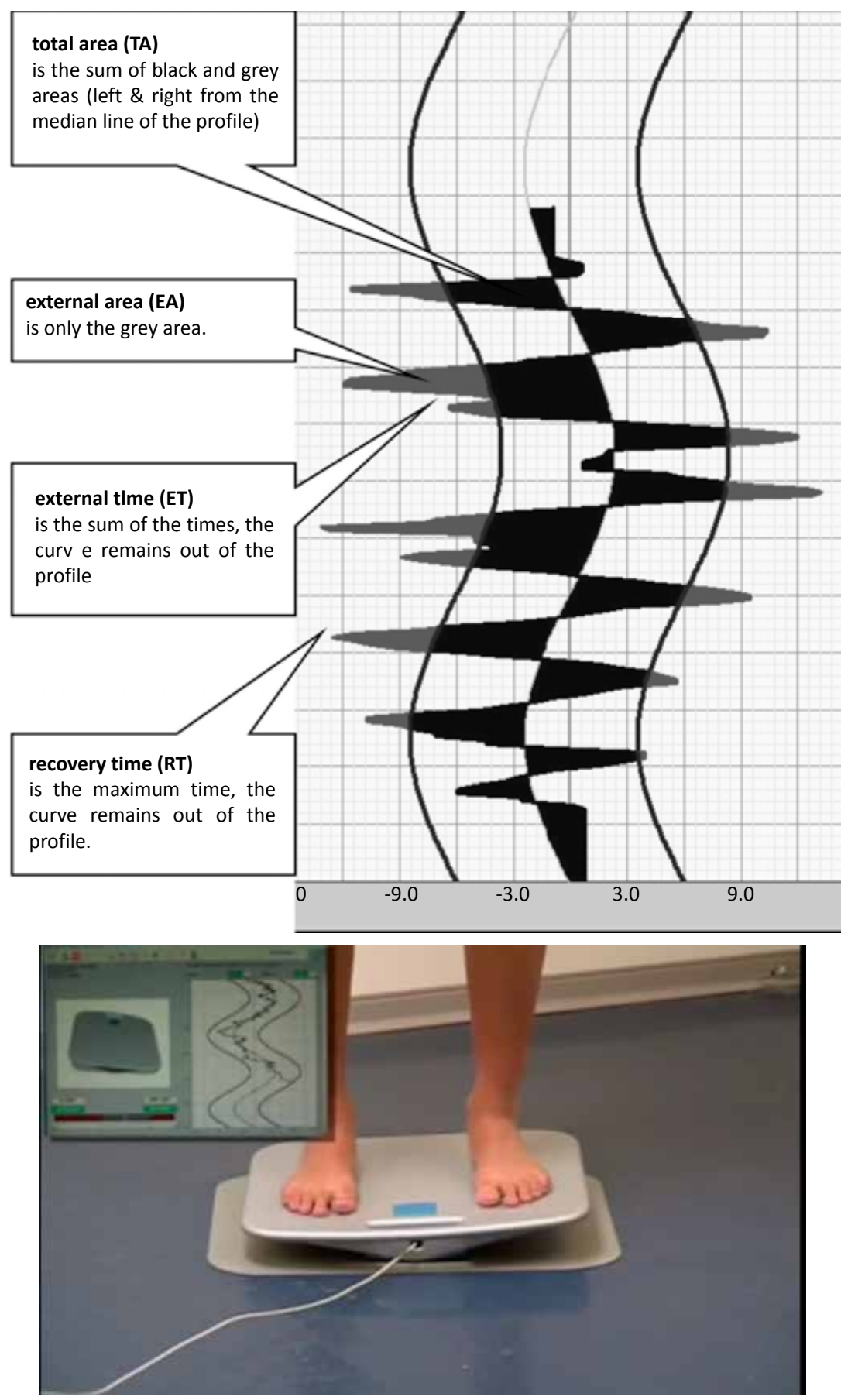

Figure 2. Libra See Saw Balancing Board.

minutes rest between stations have been given (Table 3) [51].

C-Strength Training (7th and 8th Week): The participants have implemented Back squat and dead lift movements. Suitably to traditional strength training, 4 sets with 80-85 percentage of 1 max turn; 6-8 turns have been implemented. 1-2 minutes rest between sets and 2-3 minutes rest between stations have been given (Table 3) [51].

Basketball Technical and Tactical Training (1st and 8th Week): Basketball players out of the participants in test and control groups have continued basketball trainings two days a week. Basketball training has been performed with 90 minutes period of time every day. The training has included technic drills, tactic drills, shot drills, and dribble drills. In this training structures, long HIIT (High Intensity Interval Training; $1-2 ; 1$ ) and short HIIT (High Intensity Interval Training; 1; 3-6) have been implemented. In the content of training at the same time $1 \mathrm{v} 0,2 \mathrm{v} 0,3 \mathrm{v} 0$; ve $1 \mathrm{v} 1,2 \mathrm{v} 2,3 \mathrm{v} 3,4 \mathrm{v} 4,5 \mathrm{v} 5$ variations have been included (Table 3) [52].

Statistical Analysis:

The data has been prepared in MS Excel (2007) program for Windows and the graphics for the study have been drawn. The statistical analysis has been created in SPSS (17. 0) program for Windows. In repetitive 
measurement variance analysis time group $\mathrm{x}$ interaction has been evaluated. The conditions whether the data has normal distribution or not before the hypothesis to identify the suitable test have been investigated. The significant level has been evaluated as $\mathrm{p}<0.05$.

\section{Results}

When obtained results have been evaluated, when comparing the difference between pre and final test average values of control group and test group in $\mathrm{VO}_{2 \mathrm{Max}}$ Estimate $(\mathrm{Mg} / \mathrm{kg} / \mathrm{min})$ and Met values in group $\mathrm{x}$ time interaction dimension, the difference between the groups has been found statistically significant $(F 1,28 ; p<0.05)$ (Table 4).

Table 3. 8 weeks Training Program
According to the results of simple effect test, while the alteration that has come out between $\mathrm{VO}_{2 \mathrm{Max}}$ Estimate $(\mathrm{Mg} / \mathrm{kg} / \mathrm{min})$ and MET values in pre and final test values of test group has been found statistically significant according to results of the analysis, the change in control group has not been found statistically significant (Table $5)$.

When obtained results have been evaluated, when comparing the difference between pre and final test average values of test group and control group in body fat percentage values group $\mathrm{x}$ time interaction dimension, the difference between the groups has been found statistically significant $\left(\mathrm{F}_{1,28} ; 4.087 ;<0.05\right)$ (Table 6).

According to the results of simple effect test the

TRAINING PROGRAM

\begin{tabular}{|c|c|c|c|c|c|c|}
\hline \multirow[b]{2}{*}{ WEEKS } & & \multicolumn{5}{|l|}{ Days } \\
\hline & & Monday & Tuesday & Wednesday & Thursday & Friday \\
\hline \multirow[t]{4}{*}{ 1st and 2 nd. } & Morning & A-Functional & & A-Functional & & A-Functional \\
\hline & & & Basketball & & Basketball & \\
\hline & Evening & & Technical and & & Technical and & \\
\hline & & & Tactical Training & & Tactical Training & \\
\hline \multirow{3}{*}{ 3rd and 4th } & & B-Functional & A-Strength & B-Functional & A-Strength & B-Functional \\
\hline & Morning & Training & Training & Training & Training & Training \\
\hline & Evening & $\begin{array}{l}\text { Basketball } \\
\text { Technical } \\
\text { and Tactical } \\
\text { Training }\end{array}$ & & & $\begin{array}{l}\text { Basketball } \\
\text { Technical and } \\
\text { Tactical Training }\end{array}$ & \\
\hline \multirow{3}{*}{ 5th and 6th } & Morning & C-Functional & B-Strength & C-Functional & B-Strength & C-Functional \\
\hline & Mlornıng & Training & Training & Training & Training & Training \\
\hline & Evening & $\begin{array}{l}\text { Basketball } \\
\text { Technical } \\
\text { and Tactical } \\
\text { Training }\end{array}$ & & & $\begin{array}{l}\text { Basketball } \\
\text { Technical and } \\
\text { Tactical Training }\end{array}$ & \\
\hline \multirow[t]{4}{*}{ 7th and 8th } & Morning & $\begin{array}{l}\text { C-Functional } \\
\text { Training }\end{array}$ & $\begin{array}{l}\text { C-Strength } \\
\text { Training }\end{array}$ & $\begin{array}{l}\text { C-Functional } \\
\text { Training }\end{array}$ & $\begin{array}{l}\text { C-Strength } \\
\text { Training }\end{array}$ & $\begin{array}{l}\text { C-Functional } \\
\text { Training }\end{array}$ \\
\hline & & Basketball & & & Basketball & \\
\hline & Evening & Technical & & & $\begin{array}{l}\text { Basketioall } \\
\text { Technical and }\end{array}$ & \\
\hline & & $\begin{array}{l}\text { and Tactical } \\
\text { Training }\end{array}$ & & & Tactical Training & \\
\hline
\end{tabular}

Table 4. $\mathrm{VO}_{2 \mathrm{Max}}$ Estimate $\mathrm{Mg} / \mathrm{kg} / \mathrm{min}$ and Met values group $\mathrm{x}$ time interaction

\begin{tabular}{|c|c|c|c|c|c|}
\hline Group & Measurement & $\mathbf{N}$ & Average. \pm Std. H. & $\mathbf{F}$ & $\mathbf{p}$ \\
\hline \multirow{2}{*}{ Test } & Pre test & 15 & $35.530 \pm 1.348$ & \multirow{4}{*}{21.357} & \multirow{4}{*}{$.000^{*}$} \\
\hline & Final test & 15 & $43.800 \pm 1.148$ & & \\
\hline \multirow{2}{*}{ Control } & Pre test & 15 & $37.910 \pm 1.348$ & & \\
\hline & Final test & 15 & $39.500 \pm 1.148$ & & \\
\hline \multirow{2}{*}{ Test } & Pre test & 15 & $10.140 \pm .386$ & \multirow{4}{*}{20.035} & \multirow{4}{*}{$.000^{*}$} \\
\hline & Final test & 15 & $12.520 \pm .333$ & & \\
\hline \multirow{2}{*}{ Control } & Pre test & 15 & $10.820 \pm .386$ & & \\
\hline & Final test & 15 & $11.350 \pm .333$ & & \\
\hline
\end{tabular}

$* p<0.05$ 
Table 5. $\mathrm{VO}_{2 \mathrm{Max}}$ Estimate $\mathrm{Mg} / \mathrm{kg} / \mathrm{min}$ and Met values simple effect test results

\begin{tabular}{|c|c|c|c|c|}
\hline \multirow{2}{*}{ Group } & Measurement & Measurement & \multirow{2}{*}{ Mean Dif. \pm Std. H. } & \multirow{2}{*}{$\mathbf{p}$} \\
\hline & -1 & -2 & & \\
\hline Test & Final test & Pre test & $8.270 \pm 1.022$ & $.000^{*}$ \\
\hline Control & Final test & Pre test & $1.590 \pm 1.022$ & 0.131 \\
\hline Test & Final test & Pre test & $2.380 \pm .292$ & $.000^{*}$ \\
\hline Control & Final test & Pre test & $.530 \pm .292$ & 0.08 \\
\hline
\end{tabular}

$* p<0.05$

Table 6. Body Fat Percentage Values group $\mathrm{x}$ time interaction

\begin{tabular}{|c|c|c|c|c|c|}
\hline Group & Measurement & $\mathbf{N}$ & Average \pm Std. H. & $\mathbf{F}$ & $\mathbf{p}$ \\
\hline \multirow{2}{*}{ Test } & Pre test & 15 & $14.960 \pm 1.118$ & \multirow{4}{*}{7.901} & \multirow{4}{*}{$.009^{*}$} \\
\hline & Final test & 15 & $14.516 \pm 1.037$ & & \\
\hline \multirow{2}{*}{ Control } & Pre test & 15 & $11.273 \pm 1.118$ & & \\
\hline & Final test & 15 & $11.272 \pm 1.037$ & & \\
\hline
\end{tabular}

$* \mathrm{p}<0.05$

Table 7. Body Fat Percentage values simple effect test results

\begin{tabular}{lllll}
\hline Group & Measurement (1) & Measurement (2) & Mean Dif. \pm Std. H. & P \\
\hline Test & Final test & Pre test & $-.443 \pm .111$ & $.010^{*}$ \\
Control & Final test & Pre test & $-.001 \pm .111$ & .992 \\
\hline
\end{tabular}

$* p<0.05$

alteration that has come out between Body Fat Percentage pre and final test values has been found statistically significant according to results of the analysis. However, no significant change in control group has been identified (Table 7).

When obtained results have been evaluated, when comparing the difference between pre and final test average values only in left foot lateral balance scores group $\mathrm{x}$ time interaction dimension, the difference between the groups has been found statistically significant (F1, 28;4, $320 ; \mathrm{p}<0,05$ ) (Table 8).

According to the results of simple effect test, while the alteration that has come out between pre and final test in right lateral balance and Both Feet Lateral Balance in test group has been found statistically significant, the alteration between pre and final test values in all balance values in control group has been found statistically significant according to results of the analysis (Table 9).

\section{Discussion}

In this study, while the developmental difference in $\mathrm{VO}_{2 \mathrm{ax}}$ Estimate $(\mathrm{mg} / \mathrm{kg} / \mathrm{min}), \mathrm{MET}$, body fat percentage and left foot lateral balance test values in both test and control groups when comparing group $\mathrm{x}$ time interaction has been found statistically significant, no significant difference has been found in both feet lateral balance, right foot lateral balance and both feet transfer balance measurements. When examining pre and final measurement values of simple effect test group directed to the effect of training, while the difference in $\mathrm{VO}_{2 \mathrm{Max}}$
Estimate ( $\mathrm{mg} / \mathrm{kg} / \mathrm{min})$, MET, body fat percentage, both feet lateral balance and right foot lateral balance values has been found significant, no significant difference in left foot balance and both feet transfer balance values has been found. When pre and final measurement values of control group have been examined, while significant difference has been found in both feet lateral balance, right-left foot lateral balance and both feet lateral balance values, no significant difference has been found in $\mathrm{VO}_{2 \mathrm{Max}}$ Estimate $(\mathrm{mg} / \mathrm{kg} / \mathrm{min})$, MET, body fat percentage values.

Shaik and Mondal in their study have stated that functional training has improved speed, endurance, strength, explosive strength, flexibility and agility [5]. Neves et al. on their study implemented on women have stated that there is a development in oxygen capacity of circuit HIIT group at the end of 9 weeks Circuit combined and Circuit HIIT trainings [53]. Kibele and Behm have defined that 7 weeks functional training is similar to aerobic development at the end of traditional resistance training program [54]. Kliszczewicz et al. in their research have stated that there is an improvement in aerobic capacity after 4 weeks high intensity mixed mode programed resistance and aerobic based exercise [55]. Many research findings have pointed out that Circuit HIIT training model has developed $\mathrm{VO}_{2}$ Peak parameters $[49,56]$. Current literature findings show parallelism with our research findings.

Tomljanović, et al in their study have identified that there is no difference in either of two training models in anthropometric after 8 weeks functional and resistance 
Table 8. Group $x$ time interaction according to balance test values

\begin{tabular}{|c|c|c|c|c|c|c|}
\hline Test & Group & Measurement & $\mathbf{N}$ & Average. \pm Std. H. & $\mathbf{F}$ & p \\
\hline \multirow{4}{*}{$\begin{array}{l}\text { Both Feet } \\
\text { Lateral } \\
\text { Balance }\end{array}$} & \multirow{2}{*}{ Test } & Pre test & 15 & $8.930 \pm .582$ & \multirow{4}{*}{1.596} & \multirow{4}{*}{0.217} \\
\hline & & Final test & 15 & $6.320 \pm .593$ & & \\
\hline & \multirow{2}{*}{ Control } & Pre test & 15 & $12.900 \pm .582$ & & \\
\hline & & Final test & 15 & $11.090 \pm .593$ & & \\
\hline \multirow{4}{*}{$\begin{array}{l}\text { Right Foot } \\
\text { Lateral } \\
\text { Balance }\end{array}$} & \multirow{2}{*}{ Test } & Pre test & 15 & $6.860 \pm .555$ & \multirow{4}{*}{0.019} & \multirow{4}{*}{0.891} \\
\hline & & Final test & 15 & $5.290 \pm .547$ & & \\
\hline & \multirow{2}{*}{ Control } & Pre test & 15 & $10.380 \pm .555$ & & \\
\hline & & Final test & 15 & $8.740 \pm .547$ & & \\
\hline \multirow{4}{*}{$\begin{array}{l}\text { Left Foot } \\
\text { Lateral } \\
\text { Balance }\end{array}$} & \multirow{2}{*}{ Test } & Pre test & 15 & $6.230 \pm .473$ & \multirow{4}{*}{47.641} & \multirow{4}{*}{$0.010^{*}$} \\
\hline & & Final test & 15 & $6.120 \pm .529$ & & \\
\hline & \multirow{2}{*}{ Control } & Pre test & 15 & $10.140 \pm .473$ & & \\
\hline & & Final test & 15 & $8.050 \pm .529$ & & \\
\hline \multirow{4}{*}{$\begin{array}{l}\text { Both Feet } \\
\text { Transfer } \\
\text { Balance }\end{array}$} & \multirow{2}{*}{ Test } & Pre test & 15 & $9.630 \pm .725$ & \multirow{4}{*}{1.031} & \multirow{4}{*}{0.319} \\
\hline & & Final test & 15 & $8.980 \pm .676$ & & \\
\hline & \multirow{2}{*}{ Control } & Pre test & 15 & $10.940 \pm .725$ & & \\
\hline & & Final test & 15 & $9.460 \pm .676$ & & \\
\hline
\end{tabular}

${ }^{*} p<0.05$

Table 9. Simple effect test results according to balance test values

\begin{tabular}{llllll}
\hline \multirow{2}{*}{ Test } & Group & Measurement & Measurement & Mean Dif. \pm Std. $\mathbf{H .}$ & $\mathbf{p}$ \\
\cline { 2 - 5 } $\begin{array}{l}\text { Both Feet } \\
\text { Lateral Balance }\end{array}$ & Test & Final test & Pre test & $-2.610 \pm .448$ & $0.000^{* *}$ \\
\hline $\begin{array}{l}\text { Right Foot } \\
\text { Lateral Balance }\end{array}$ & Control & Final test & Pre test & $-1.810 \pm .448$ & $0.000^{* *}$ \\
\hline $\begin{array}{l}\text { Left Foot } \\
\text { Lateral Balance }\end{array}$ & Cost & Final test & Pre test & $-1.570 \pm .357$ & $0.000^{* *}$ \\
\hline $\begin{array}{l}\text { Both Feet } \\
\text { Transfer Balance }\end{array}$ & Fest & Final test & Pre test & $-1.640 \pm .357$ & $0.000^{* *}$ \\
\hline
\end{tabular}

$* p<0.05$

trainings [57]. They have stated that decrease in the measurements of traditional training group and increase in functional training group have been observed. The decrease in traditional group has been explained with the high intensity of training. Serin and Ziyagil have expressed that there is a decrease in a significant level in body fat percentage values in men after 8 weeks squat exercise program [43]. Neves et al. in their study conducting 8 weeks functional training implementations in Circuit format on female participants have seen that there is a decrease in body mass index and fat rates [53]. Doğan et al in their study implemented on 18-30 years old football players have stated that significant decrease in body mass index and body weight values of test group compared to control group after 8 weeks core training [58]. Heinrichet al have expressed that there is no significant alteration in body fat percentage values for both groups after 8 weeks high intensity functional strength training and medium level aerobic strength training implementations [59]. When literature has been examined, the studies conducted by Serin and Ziyagil, Neves et al and Doğan et al. show parallelism with our study [43, 53, 58]. However, the studies by Tomljanović, et al and Heinrichet al have not been supporting [57, 59]. When considering the content and duration of functional trainings, it has been thought the effect of body fat percentage will be more effective. 
Whitehurst et al have stated that functional training model in balance development is numerically better than traditional training [60]. Kibele and Behm have pointed out that 7 weeks functional training is similar to dynamic balance development after traditional resistance training program [54]. Vreede et al have expressed that leg strength, balance and coordination have improved with 12 weeks functional training.

Pacheco et al in their study in which they researched the effect of functional training on balance have identified that there is a significant improvement in balance values of the individuals who have the average $(54.75 \pm 8.84$ years) [62]. Oliver and Brezzo in their study have stated that improvement in balance scores has been observed after functional balance training for collegiate female volleyball players and football players in both groups [17]. Boztepe and Erkut in their study conducted with active football players have identified that the increase in balance values of functional training group is in a significant level compared to traditional training group [63]. In also current literature findings, it has been exhibited that functional training develops not only strength and resistance but also flexibility, balance, coordination and deep sensory and besides it is an effective training model in terms of empowering the performance [64-67]. When literature findings have been examined, increase in balance values has been seen in the studies where functional training model is used. The research supports our results. In view of group $\mathrm{x}$ time interaction, while left foot lateral dynamic balance shows development in both groups, it has been seen that both feet lateral and right foot lateral dynamic balance have been affected in a positive way in test group in simple effect. That there are more movement combinations towards lateral side rather than transfer side in basketball branch and there is more pressure on single foot when performing technics such as turnstile for scoring to basket bring balance concept into the forefront.

\section{Conclusions}

In functional training approach, it has been thought that the efficiency will be increase on the condition of its compatibility with the technic values of sports branch. It has been seen that placing functional trainings in basketball yearly training periodizing will contribute to aerobic power, balance and body fat percentage values. Increasing in anaerobic capacity has been affecting aerobic capacity at the same time. The efficiency of balance technics in contributing to game scores is important.

\section{Conflict of interest}

Authors declare no conflict of interest.

\section{References}

1. Weiss T, Kreitinger J, Wilde $H$, Wiora C, Steege $M$, Dalleck L, Janot J. Effect of functional resistance training on muscular fitness outcomes in young adults, Journal of Exercise Science \& Fitness. 2010; 8(2): 113-122. https://doi.org/10.1016/S1728-869X(10)60017-2

2. Stenger, L. What is functional/neuromotor fitnes. ACSM's Health \& Fitness Journal: 2018; 22(6): 35-43. https://doi.org/10.1249/FIT.0000000000000439

3. Young WB. Transfer of strength and power training to sports performance. International journal of sports physiology and performance: 2006; 1(2): 74-83. https://doi.org/10.1123/ijspp.1.2.74

4. Boyle M. Functional Training for Sports. Champaign (IL): Human Kinetics; 2004

5. Shaikh A, Mondal S. Effect of functional training on physical fitness components on college male students-a pilot study. Journal of Humanities and Social Science: 2012; 1(2): 01-05. https://doi.org/10.9790/0837-0120105

6. Silva-Grigoletto MED, Brito CJ, Heredia JR. Functional training: functional for what and for whom? Revista Brasileira de Cineantropometria \& Desempenho Humano, 2014; 16(6): 714-719. https://doi.org/10.5007/1980-0037.2014v16n6p714

7. Beckham SG, Harper M. Functional training: fad or here to stay. ACSM's Health \& Fitness Journal, 2010;14(6): 24-30. https://doi.org/10.1249/FIT.0b013e3181f8b3b7

8. Green ES, Williams ER, McCully KK, Jenkins NT. Enhanced Strength, Power, Work Capacity, and Fatigue Resistance in High Intensity Functional Training Athletes. The FASEB Journal: 2019; 33: 695-11. https://doi.org/10.1096/fasebj.2019.33.1

9. Gencer YE, Iğdır EC, Şahin S, Eriş F. Effects of 8 Weeks of Plyometric Exercise on Certain Physiological
Parameters and Performance of Swimmers. Journal of Education and Training Studies: 2018;6(7): 49-54. https://doi.org/10.11114/jets.v6i7.3194

10.Smith M, Box A, Hoffstetter W, Mangine, G. Skillbased Performance Improves After 16-weeks of High-intensity Functional Training. Medicine \& Science in Sports \& Exercis, 2016; 48(5S): 161. https://doi.org/10.1249/01.mss.0000485484.79225.4e

11. Ribeiro AS, Daniel W, Godinho Filho N, FSLV RE, Silva RD, Viera LL, Palomares, EDG. Comparison Between Functional Training And Resistance Training For Balance. Journal of Sports and Physical Education, 2016; 3(6): 8-12. https://doi.org/10.9790/6737-03062124

12.Sparkes R, Behm DG. Training adaptations associated with an 8-week instability resistance training program with recreationally active individuals. The Journal of Strength \& Conditioning Research, 2010; 24(7): 1931-1941. https://doi.org/10.1519/JSC.0b013e3181df7fe4

13.Tomljanović M, Spasić M, Gabrilo G, Uljević O, Foretić N. Effects of five weeks of functional vs. traditional resistance training on anthropometric and motor performance variables. Kinesiology: International Journal of Fundamental and Applied Kinesiology, 2011; 43(2): 145-154.

14.Caglayan A, Ozbar, N. The Examination of The Effects of Functional Training Program Applied on Instable Ground on Anaerobic Capacities of Elite Martial Arts Athletes. European Journal of Education Studies, 2017; 3(11). https://doi.org/10.5281/zenodo.1133471

15.Josephson MD, Williams JG. Functional-strengthening: A pilot study on balance control improvement in community-dwelling older adults. Montenegrin Journal of Sports Science and Medicine, 2017; 6(2): 75-78. https://doi.org/10.26773/mjssm.2017.09.010

16.Herman K, Barton C, Malliaras P, Morrissey D. The 
effectiveness of neuromuscular warm-up strategies, that require no additional equipment, for preventing lower limb injuries during sports participation: a systematic review. BMC Medicine, 2012; 10(1): 75. https://doi.org/10.1186/1741-7015-10-75

17. Oliver GD, Di Brezzo R. Functional balance training in collegiate women athletes. The Journal of Strength \& Conditioning Research, 2009; 23(7): 2124-2129. https://doi.org/10.1519/JSC.0b013e3181b3dd9e

18.Zech A, Hübscher $\mathrm{M}$, Vogt L, Banzer W, Hänsel F, Pfeifer K. Balance training for neuromuscular control and performance enhancement: a systematic review. Journal of Athletic Training, 2010; 45(4): 392-403. https://doi.org/10.4085/1062-6050-45.4.392

19.Song HS, Woo SS, So WY, Kim KJ, Lee J, Kim JY. Effects of 16-week functional movement screen training program on strength and flexibility of elite high school baseball players. Journal of Exercise Rehabilitation, 2014; 10(2): 124. https://doi.org/10.12965/jer.140101

20.Sheerin KR, Hume PA, Whatman C. Effects of a lower limb functional exercise programme aimed at minimising knee valgus angle on running kinematics in youth athletes. Physical Therapy in Sport, 2012; 13(4): 250-254. https://doi.org/10.1016/j.ptsp.2012.01.003

21.Barbieri FA, Rodrigues ST, Polastri PF, Barbieri RA, de Paula PHA, Milioni F, Zagatto AM. High intensity repeated sprints impair postural control, but with no effects on free throwing accuracy, in under-19 basketball players. Human Movement Science, 2017; 54:191-196. https://doi.org/10.1016/j.humov.2017.04.010

22.Rostam R, Yildırım A, Gencer YG. Analysis of the Effect of Dynamic Stability on Shot Accuracy in Basketball. OPUS Uluslararast Toplum Araştırmalart Dergisi, 2019; 10(17): 1476-1494. https://doi.org/10.16466/opus.534271

23. Bressel E, Yonker JC, Kras J, Heath EM. Comparison of static and dynamic balance in female collegiate soccer, basketball, and gymnastics athletes. Journal of Athletic Training: 2007; 42(1): 42-50.

24. Tabatabaee RA, Rahnama N, Khayambashy K, Dehkhoda MR, Shahi MHP. The Effect of Ankle TheraBand Training on Dynamic Balance Index Among Elite Male Basketball Players. Asian Journal of Sports Medicine, 2019; 10(2). https://doi.org/10.5812/asjsm.82011

25.Serin E. Relationship Between The Hip Anatomy and Sportıng Performance. European Journal of Physical Education and Sport Science, 2017; 3(10). https://doi.org/10.5281/zenodo.1043342

26.Gribble PA, Hertel J, Plisky P. Using the Star Excursion Balance Test to assess dynamic postural-control deficits and outcomes in lower extremity injury: a literature and systematic review. Journal of Athletic Training: 2012; 47(3): 339-357. https://doi.org/10.4085/1062-6050-47.3.08

27.Bullock GS, Arnold TW, Plisky PJ, Butler RJ. Basketball players dynamic performance across competition levels. The Journal of Strength \& Conditioning Research, 2018; 32(12): 3528-3533. https://doi.org/10.1519/JSC.0000000000001372

28.Gonzalo-Skok O, Serna J, Rhea MR, Marín PJ. Age differences in measures of functional movement and performance in highly youth basketball players. International Journal of Sports Physical Therapy, 2017;12(5): 812-821. https://doi.org/10.26603/ijspt20170812

29.Long M. The Effects of a Six Week Lumbopelvic Control and Balance Training Program in High School Basketball Players. Virginia: West Virginia Üniversity Press; 2017.
30.Minoonejad H, Ardakani MK, Rajabi R, Wikstrom EA, Sharifnezhad A. Hop stabilization training improves neuromuscular control in college basketball players with chronic ankle instability: a randomized controlled trial. Journal of Sport Rehabilitation, 2019; 28(6): 576-583. https://doi.org/10.1123/jsr.2018-0103

31.Tetik S, Koç M, Atar Ö, Koç H. An analysıs of the correlation between static balance performance and game value scale in basketball players. Turkish Kick Boxing Federation Journal of Sport Science: 2013; 6(1): 9-18.

32.GencerY,IğdırE,TemürHM. SeyhanS. Doeshand gripstrength affect shot hit rates?. Turkish Studies, 2019; 14(1): 371-380. https://doi.org/10.7827/TurkishStudies.13432

33.Özer Ö. Investigation of Strength, Flexibility and Balance Parameters withPerformanceDimensioninBasketballPlayers. Journal of Education and Learning, 2019;8(5): 1927-5269. https://doi.org/10.5539/jel.v8n5p225

34.Günay M, Tamer K, Cicioğlu İ. Spor fizyolojisi ve Performans Ölçümü [Sports physiology and Performance Measurement]. Ankara: Gazi Bookstore; 2013. (In Turkish)

35.De Araujo GG, De Barros Manchado-Gobatto F, Papoti M, Camargo BHF, Gobatto CA. Anaerobic and aerobic performances in elite basketball players. Journal of Human Kinetics, 2014; 42(1): 137-147. https://doi.org/10.2478/hukin-2014-0068

36.Serin E. Anaerobik dayanıklılık ile dikey sıçrama arasındaki ilişki [The relationship between anaerobic endurance and vertical jump]. Konya: Konya Selcuk University Edition; 2015. (In Turkish)

37.Marcelino PR, Aoki MS, Arruda AF, Freitas CG, Mendez-Villanueva A, Moreira A. Does small-sidedgames' court area influence metabolic, perceptual, and physical performance parameters of young elite basketball players? Biology of Sport: 2016; 33(1): 37. https://doi.org/10.5604/20831862.1180174

38.Hoffman JR. The influence of aerobic capacity on anaerobic performance and recovery indices in basketball players. The Journal of Strength \& Conditioning Research, 1999;13(4): 407- 411. https://doi.org/10.1519/00124278-199911000-00018

39. McInnes SE, Carlson JS, Jones CJ, McKenna MJ. The physiological load imposed on basketball players during competition. Journal of Sports Sciences, 1995; 13(5): 387-397. https://doi.org/10.1080/02640419508732254

40.Gaurav V, Singh M, Singh S. Anthropometric characteristics, somatotyping and body composition of volleyball and basketball players. Journal of Physical Education and Sports Management, 2010;1(3): 28-32.

41.Kenney WL, Wilmore JH, Costill, DL. Physiology of sport and exercise. Champaign, IL: Human Kinetics; 2015.

42.Masanovic B, VukcevicA, Spaic S. Sport-specific morphology profile: Differences in anthropometric characteristics between elite soccer and basketball players. Journal of Anthropology of Sport and Physical Education, 2018; 2(3): 43-47. https://doi.org/10.26773/jaspe. 181008

43. Serin E, Ziyagil, MA. The effect of 8 Weeks squat exercise program on body composition in young males. International Journal of Disabilities Sports and Health Sciences, 2020; 3(1): 28-32. https://doi.org/10.33438/ijdshs. 716858

44.Maximal Ramp Test [Internet]. 2019. [updated 2019; cited 2020 May 23]. Available from: https://cdn.wattbike.com/ uploads/uk/file_manager/max-ramp.pdf

45.Störer TW, Davis JA, Caiozzo VJ. Accurate prediction of VO2max in cycle ergometry. Med Sci Sports Exercices. 1990; 22(5): 704-712. 
https://doi.org/10.1249/00005768-199010000-00024

46.Açıkada C, Erge E, Alpar R, Sarpyener K. Investigation Of The Relationship Between The Body Composition And The Trunk Muscle Strength Of Male Athletes. Spor Bilimleri Dergisi: 1991;2(2): 1-25.

47.Tchórzewski D, Bujas P, Jankowicz-Szymańska A. Body posturestability in ski bootsunderconditions of unstable supporting surface. Journal of Human Kinetics, 2013; 38(1), 33-44. https://doi.org/10.2478/hukin-2013-0043

48.Tchórzewski D, Jaworski J, Bujas P. Influence of longlastingbalancing on unstablesurface on changes in balance. Human Movement, 2010, 11(2): 144-152. https://doi.org/10.2478/v10038-010-0022-2

49. Sperlich B, Wallmann-Sperlich B, Zinner C, Von Stauffenberg V, Losert H, Holmberg HC. Functional high-intensity circuit training improves body composition, peak oxygen uptake, strength, and alters certain dimensions of quality of life in overweight women. Frontiers in Physiology: 2017; 8: 172. https://doi.org/10.3389/fphys.2017.00172

50.Bompa TO, Di Pasquale M, Cornacchia L. Serious strength training. Human Kinetics; 2012.

51.Mangine GT, Hoffman JR, GonzalezAM, Townsend JR, Wells AJ, JajtnerAR, ae al. The effect of training volume and intensity on improvements in muscular strength and size in resistancetrained men. Physiological Reports, 2015; 3(8): e12472. https://doi.org/10.14814/phy2.12472

52.Schelling X, Torres-Ronda L. Conditioning for basketball: Quality and quantity of training. Strength \& Conditioning Journal, 2013;35(6): 89-94. https://doi.org/10.1519/SSC.0000000000000018

53.Neves LM, Fortaleza AC, Rossi FE, Diniz TA, Freitas JI. Effect of a short-term functional training program on body composition in postmenopausal women. Revista Brasileira de Ginecologia e Obstetricia, 2014; 36(9): 404-409. https://doi.org/10.1590/SO100-720320140005073

54.Kibele A, Behm DG. Seven weeks of instability and traditional resistance training effects on strength, balance and functional performance. The Journal of Strength \& Conditioning Research, 2009; 23(9): 2443-2450. https://doi.org/10.1519/JSC.0b013e3181bf0489

55.Kliszczewicz B, McKenzie M, Nickerson B. Physiological adaptation following four-weeks of high-intensity functional training. Vojnosanitetski Pregled, 2019;76(3): 272-277. https://doi.org/10.2298/VSP170228095K

56.Stöggl T, Sperlich B. Polarized training has greater impact on key endurance variables than threshold, high intensity, or high volume training. Frontiers in Physiology, 2014; 5: 3. https://doi.org/10.3389/fphys.2014.00033

57.Tomljanović M, Spasić M, Gabrilo G, Uljević O, Foretić N. Effects of five weeks of functional vs. traditional resistance training on anthropometric and motor performance variables. Kinesiology: International Journal of Fundamental and Applied, 2011; 43(2): 145-154.

58.Doğan G, Mendeș B, Akcan F, Tepe A. The effect of eightweek core training on some physical and physiological parameters of football players. Niğde Üniversitesi Beden Eğitimi ve Spor Bilimleri Dergisi, 2016;10(1): 1-12.

59.Heinrich KM, Patel PM, O’Neal JL, Heinrich BS. Highintensity compared to moderate-intensity training for exercise initiation, enjoyment, adherence, and intentions: an intervention study. BMC Public Health, 2014; 14(1): 789. https://doi.org/10.1186/1471-2458-14-789

60. Whitehurst MA, Johnson BL, Parker CM, Brown LE, Ford AM. The benefits of a functional exercise circuit for older adults. Journal of Strength and Conditioning Research, 2005; 19(3): 647-651. https://doi.org/10.1519/00124278-200508000-00027

61.De Vreede PL, Samson MM, Van Meeteren NLU, Duursma SA, Verhaar HJJ. Functional-Task Exercise Versus Resistance Strength Exercise to Improve Daily Function in Older Women: A Randomized, Controlled Trial: exercise to improve da1ly function in older women. Journal of the American Geriatrics Society, 2005;53:2-10. https://doi.org/10.1111/j.1532-5415.2005.53003.x

62.Pacheco MM, Teixeira LAC, Franchini E, Takito MY. Functional vs. strength training in adults: specific needs define the best intervention. International Journal of Sports Physical Therapy: 2013;8(1): 34-43.

63.Boztepe A. Erkut O. Evaluation of the effect of functional training on athletic performance in young soccer players: [Master Thesis]. Istanbul: Istanbul University, Institute of Social Sciences; 2018.

64.Blasco-Lafarga C, Martinez-Navarro I, Pablos C. Six weeks of functional training enhances balance, strength and cardiovascular endurance among postmenopausal women. In Journal of Aging and Physical Activity, 2012; 20: 254-255.

65.Doigo S, King GA. Effects of functional training in an older adult fitness program. Research Quarterly for Exercise and Sport, 2008; 79(1): 14-20.

66.Cook G. Athletic Body in Balance. USA:Human Kinetics; 2003.

67.Lohne-Seiler H, Torstveit MK, Anderssen SA. Traditional- versus Functional Strength Training. Effects on Muscular Strength and Power among Elderly. $J$ AgingPhysAct, 2012; 21(1): 51-70. https://doi.org/10.1123/japa.21.1.51

68. Yıldız S, Pınar S, Gelen E. Functional Training Approach for Children Tennis Players. Clinical and Experimental Health Sciences, 2014; 4:10-17. 


\section{Information about the authors:}

Ali Türker; (Corresponding Author); https://orcid.org/0000-0001-8127-2961; a.turker@alparslan.edu.tr; School of Physical Education and Sports; Muş, Turkey.

Oğuzhan Yüksel; https://orcid.org/0000-0002-4172-8298; oguzhan.yuksel@dpu.edu.tr; School of Physical Education and Sports; Kütahya, Turkey.

Cite this article as:

Türker A, Yüksel O. The effect of functional and supportive classic strength trainings in basketball players on aerobic strength, dynamic balance and body composition. Pedagogy of Physical Culture and Sports, 2021;25(1):47-58. https://doi.org/10.15561/26649837.2021.0107

This is an Open Access article distributed under the terms of the Creative Commons Attribution License, which permits unrestricted use, distribution, and reproduction in any medium, provided the original work is properly cited (http://creativecommons.org/licenses/by/4.0/deed.en).

Received: 11.06.2020

Accepted: 20.07.2020; Published: 25.02.2021 